\title{
Tissue engineering of the anterior cruciate ligament and meniscus using acellularized scaffolds
}

\author{
Gunther H. Sandmann and Thomas Tischer \\ Department of Orthopaedic and Trauma Surgery \\ Technische Universität München
}

Germany

\begin{abstract}
Injuries to the anterior cruciate ligament (ACL) and the meniscus are very common. Both the ACL and the meniscus play a crucial role in the complex biomechanics of the knee and operative treatment is often necessary. For example, in the US approximately 200,000 ACL reconstructions are performed annually. Usually, autogenous tendons like the mid- third of the patellar tendon or the hamstring tendons (semitendinosus/gracilis) are used. Nevertheless, the availability of autogenous tendons for ACL reconstruction is limited as well as the possibilities of meniscus repair. Ligament and meniscus allografts often show problems regarding long-term stability, immunological reactions and possible transmission of infectious diseases, whereas synthetic materials can cause foreign body reactions and often lack good initial biomechanical stability or fail to maintain long-term stability.

The idea of acellularizing ligaments and meniscus cartilage has arisen to remove the immunogenic cells to reduce the adverse immunological reactions. By preserving the extracellular matrix (e. g. collagen, glycosaminoglycans, proteoglycans), the main biomechanical properties are preserved and the so obtained scaffolds provide a natural environment for the ingrowing cells. The acellular scaffolds can be used as a scaffold for in vivo repopulation or can be seeded with autologous cells in vitro before implantation using different cell sources. By this, further improvement of the biochemical and biomechanical properties as well as the remodelling of the graft could be improved.

In the meantime, a variety of different methods has been described to acellularize tissues reaching from repetitive freezing/ thawing over the use of hydrostatic high pressure to different chemical methods. Only by chemical means are the cells actually removed. In terms of chemical acellularization, SDS (sodium dodecyl sulphate), Triton-X or TnbP (trinitro-butyl-phosphate) are the most popular substances, with SDS being the strongest cell removal agent for tendon and meniscus tissue. As in vitro tests have shown, tissue processing using SDS does not influence the biomechanical properties, while all cells - being responsible for the immunological effects - are removed. However, more research using in vivo animal experiments has to be performed before application in humans is possible.
\end{abstract}


This tissue engineering strategy might be suitable to satisfy the increasing demand for tissue engineered tissue coming along with the increased patients' demands in the future.

\section{Introduction}

Injuries to the ACL and the meniscus are very common and negatively influence the complex biomechanics of the knee joint. Due to the poor vascularity, both structures show limited healing capacity and surgical repair is often necessary (Arnozcky 1983, Arnozcky 1983). In the US approximately 200,000 ACL reconstructions are performed per year and the number is still growing. The golden standard is the reconstruction of the injured ACL by using autogenous tendons like the hamstring tendons (semitendinosus/gracilis) or the middle- third of the patellar or quadriceps tendon. These methods have been used for several years now and show reliable results in the long- term. However, the problem of development of osteoarthrosis in the long term is not solved yet (Lohmander 2007, Messmer 1999). So far no study exists proving a chondro-protective effect after ACL reconstruction. The reported outcome 32 years after ACL replacement is unacceptable in about $50 \%$ of cases. In accompanying meniscus lesions the outcome is even worse (Taylor 2009). Whether this is mainly due to cartilage injury at the time of accident or due to altered joint biomechanics is not known yet. So far, there exists no clear consensus, which patients benefit from ACL replacement in the long run. New techniques of ACL reconstruction like the anatomic double-bundle reconstruction (anteromedial and posterolateral bundle) and new methods of fixation might improve the outcome in the future (Kondo 2008, Zantop 2008, Brucker 2006).

Though the ACL reconstruction using autogenous tendons is currently the gold standard, some problems still remain. There is on the one hand the problem of donor site morbidity with persisting anterior knee pain and the inability to kneel, especially after the use of patellar tendon transplants (Kartus 2001). Muscle strength deficits have been found after ACL reconstruction with patellar and hamstring grafts (Aune et al. 2001; Beard et al. 2001), especially the harvesting of hamstring grafts has been found to cause muscular weakness at high knee flexion angles (Makihara et al., 2006; Nakamura et al., 2002; Tashiro et al., 2003). Furthermore the availability of autogenous tendons is limited. In multi-ligamentous knee injuries the use of allografts is often required. Different allograft ligaments may be used: bone-patella-tendon-bone, hamstring, achilles or tibialis anterior/posterior tendons. However, no differences between the used allograft tissue have been reported, whereas significant differences exist, which sterilization processes were used (Carey et al. 2009; Krych et al. 2007). In a recent systematic review comparing ACL replacement using autografts with allografts, similar medium term results were reported in non-randomized studies (Carey et al., 2009). Still, immunogenic reactions may cause degenerative alterations and the potential risk of disease transmission remains. Using standard sterilization procedures like lyophilisation (Crawford et. al, 2004) or gamma irradiation (Fideler et al. 1995; Gibbons et al. 1991) retroviruses (i.e. HIV) can hardly be destroyed.

Apart from the ligaments, the meniscus plays a crucial role in the complex biomechanics of the knee, as it works as a shock absorber and transforms joint pressure in circular meniscus tension. This is mediated by the complex structure (mainly its circular collagen network) of the meniscus. Unfortunately its healing capacities are very poor. As soon as a radial tear destroys the circular collagen network or the horns are ruptured, the meniscus looses all biomechanical function. This leads to joint overload and might end in an overuse of the 
cartilage and an early onset of osteoarthritis (Lohmander et al. 2007; Allaire et al. 2008). Many improvements have been made to reconstruct the injured meniscus, but due to its biomechanical and anatomical specialities this is still impossible in many cases.

The transplantation of meniscus allografts is a viable option but has its own problems as well (Packer et al. 2009). On the one hand there is the problem that there are too little donor organs as the meniscus of elderly people has usually degenerative alterations and can thereby not be used. Apart from the lack of organs it is difficult to get a suitable transplant fitting in size. In a recent work Van Thiel et al. 2009 could show that the fitting size of the meniscus is mainly correlated with height, weight and gender of the donor and recipient. Apart from that, the fixation is technically demanding. Because of this, the transplantation of meniscus is reserved to specialized centers. Unfortunately, long-term results still show problems due to immunogenic and degenerative alterations. Verdonk et al. (2006) examined the long- term results of meniscus transplantation clinically and radiologically and they could show, that the meniscus transplantation lead to an improvement of function and relief of pain. Nevertheless, substantial disability and knee pain were present at the follow up after 10 years. On MRI the meniscus transplants had signs of graft extrusion and an increased signal intensity indicating degeneration. The failure rate was $18 \%$ with conversion to a total arthroplasty (Verdonk 2006). Wirth et al. (2002) found similar results but could show, that deep frozen meniscal grafts were superior compared to lyophilized meniscal grafts at a follow up of 3 and 14 years. The latter even showed similar results to the control group after meniscectomy. If those problems could be solved in the future, the meniscus transplantation might gain much popularity over time.

As an alternative to allografts the use of synthetic tendon constructs (e.g. silk, Gore Tex, LAD) or meniscus prostheses $\left(\mathrm{CMI}{ }^{\circledR}\right.$, Actifit ${ }^{\circledR}$ etc.) have emerged (Martinek 2006; van Tienen et. al 2009; Zaffagnini et al., 2008). Most of the prostheses used for ACL reconstruction have failed as they showed an adverse effect on the cartilage and caused in some cases a marked synovialitis. Though their biomechanical Properties were excellent initially, most of the prostheses had the problem of degradation, tunnel widening and high failure rates after several years (Muren et al., 2005; Roolker et al., 2000). Compared to the biomechanical properties of ligaments, meniscus tissue is even more complex and not surprising, the middle to long term results of the artificial meniscus constructs show different results from one study to the other, but in general do not reach the anatomic, biomechanical results (Buma et al., 2007). So far, artificial constructs (neither ACL nor meniscus) do not reach the biomechanical properties of autologous tissue and are therefore not an ideal long- term alternative.

To improve the long-term outcome of ligament and meniscus allografts, new strategies are needed. Recently the use of extracellular matrix (ECM) scaffolds by means of acellularization of allograft tissue has become popular (Badylak et al., 2007, Badylak et al., 2009). In the following we will depict the different means of acellularization, describe our used method and give future prospects in the field of tissue engineering concerning ligament and meniscus tissue.

\section{Acellularization methods}

Recently, biologic scaffold materials composed of extracellular matrix are widely used in surgical procedures for the reconstruction of numerous tissues and organs and their use in 
orthopaedic research surgery has emerged over the last years. As scaffolds allograft or possibly xenograft tendons/meniscus are used, which are acellularized by different methods.

The basic requirements for optimal acellularization methods are:

1. removal of all cellular components as the cells (especially fibroblasts) and macrophages seem to play a crucial role in the cell- mediated immunogenic reactions, i.e. host versus graft reaction (Badylak 2008).

2. preserving the extracellular matrix which is responsible for biomechanical stability and preserving chemoatractants and providing cell attachment sites for ingrowing cells (Reing 2009).

The ECM has chemotactic factors that attract cells (Beattie et al., 2009) and supportive function for the diffusion of nutrients from the blood to the cells. Most important, the biomechanical properties are mediated by the extracellular matrix. For example, the tensile strength of tendons is mediated by its collagen I fibrils, whereas the hyaline cartilage properties are maintained by the interplay of a collagen II network with large proteoglycans (aggrecan) and negatively charged glycosaminoglycans (Tischer et al., 2002). Finally, the process of repopulation is dependent on an intact matrix and the used method should not be cytotoxic to allow cellular ingrowth. The repopulation can then happen in vitro before implantation or in vivo.

Therefore different methods have been described for the acellularization of tissues and every method has its own advantages and disadvantages. Generally, two methods can be distuingished: first methods which destroy all cells, but leave cellular components and debris and second methods which remove all the cellular components from the tissue by chemical means. In the following section, the most common methods are now discussed in more detail.

\subsection{The Gamma irradiation}

The gamma irradiation is widely used and one of the methods with the longest experience. It is very effective in destroying cells and most of the pathogenic germs. Still the gamma irradiation faces a dilemma, as doses of $3.5 \mathrm{Mrad}$ (35kGy) are needed to destroy the DNA of the HIV. However, using this amount of energy weakens the transplant, leading to loss of biomechanical stability, making it unsuitable for implantation (Fideler BM et al., 1995). In most cases irradiation doses of 1 to $2.5 \mathrm{Mrad}$ (10-25kGy) are used with a slight remaining risk of disease transmission (Buck et al., 1989). In a study by Curran it could be shown that irradiation of allografts with a dose of $20 \mathrm{kGy}$ lead to minor biomechanical properties compared to the untreated control group. Elongation was more than $27 \%$ higher and the load to failure was diminished as well (Curran et al., 2009). In a prospective randomized trial by Sun (Sun et al., 2009) the clinical outcome after ACL replacement with autograft patellar-tendon-bone and irradiated as well as non-irradiated allograft (all used allografts had been frozen) was examined. Whereas the non-irradiated allografts showed similar results to the autografts, the clinical outcome of the irradiated allografts was inferior in the clinical scores and the subjective instability was much more common in this group of patients. Taking that into account the irradiation can no longer be recommended as a 
sterilization procedure as it weakens the tissue and thereby negatively influences the biomechanical properties without reliably destroying retroviruses like HIV.

\subsection{Lyophilization/cryopreservation}

Lyophilization means the preparation of tissue by repetitive freezing and thawing. This leads to the destruction of cells, but as with irradiation the cellular components mainly remain within the extracellular matrix. The lyophiliation process has been widely used and has been proven as a simple and cheap method and is therefore most commonly used (Sass et al., 2009; Busam et. al, 2007; Lewis et al., 2008). Much work has been performed on the effects of cryopreservation on tendon allografts, but the potential adverse effects on mechanical properties and histological changes by ice crystal formation (Mahirogullari 2007). In a work by Park 2008 the effects of cryopreservation or heating on the mechanical properties and histomorphology of rat bone-patellar tendon-bones (BTBs) were investigated. BTBs were processed by cryopreservation at $-80^{\circ} \mathrm{C}$ for 3 weeks, or heating at $+80^{\circ} \mathrm{C}$ for $10 \mathrm{~min}$. Tensile testing and histomorphological examinations were performed. The cryopreservation of tendons showed less influences on their mechanical properties. When cryopreserved BTBs were fixed in frozen state by the freeze-substitution method, many widened interfibrillar spaces were observed. These results suggest that the collagen fibres of cryopreserved tendons were histomorphologically affected by ice crystals. The cryopreservation does not only affect the cellular components, but also the collagen matrix, which might have effects on the biomechanical properties as well.

However, a new work by Gelber et al. (2009) showed that the ultra structure of the meniscus is not affected by cryopreservation. Therefore, an allograft stored in that way would not alter its biomechanical properties, although its cellular viability is highly unpredictable. As the immunogenicity is cell-mediated, this imponderability makes the cryopreservation not the method of choice for tissue engineering applications, especially as the fibril diameters in frozen menisci show a thinner diameter and had a higher degree of disarray. These alterations of the collagen network can partially explain the pathological changes found in shrunken menisci after transplantation (Gelber et al., 2008).

\subsection{High pressure treatment}

The treatment of tissue with hydrostatic high pressure has emerged over the last years. By this method tissue is exposed to hydrostatic high pressure of up to $600 \mathrm{MPa}$ for 10 minutes. Diehl et al. (2006) could show that this treatment had no adverse effect on the biomechanical properties of the treated tissue. The cells were destroyed by this treatment and similar to the lyophilization the cellular components remain in the extracellular matrix and might thereby still be immunogenic. Apart from the use in tissues, high hydrostatic pressure (HHP) is widely used in the food processing industry, for example to inactivate vegetative microorganisms in meat products, milk and juice, thereby avoiding the addition of any chemical preservatives. Besides this HHP is also an attractive novel approach to effectively kill tumor cells in bone, cartilage or tendon ex vivo while leaving the tissues' mechanical properties unimpaired, thus allowing possible reimplantation of the resected tissue explants (Diehl et al., 2006, Diehl et al., 2008). However, human studies on this topic are still missing. 


\subsection{Enzymatic treatment}

Acellularization using enzymatic treatment uses various enzymes like trypsin, collagenase and others to open up the ECM and remove cellular components. For example Maier et al. described an enzymatic way of acellularization of ovine meniscus tissue (Maier et al. 2007). Forty-one menisci were used to establish their own protocol. They used distilled water, trypsin and collagenase A to acellularize meniscus samples and could show that the biomechanical and the biochemical properties were left almost unaffected. In a recently published work by Vavken et al. 2009, they could demonstrate the effectiveness of enzymatic acellularization of the ACL. Therefore, they used a combination of Trypsin, EDTA and PBS and could show that the samples could be acellularized by this enzymatic treatment. The glycosaminoglycan content was negatively affected as well.

Taking everything into account, we believe that enzymatic treatment and especially the combination of collagenase and trypsin has adverse effects on the extracellular matrix and the collagen network. These enzymes can actually destroy the ECM and this could cause problems in reseeding the acellularized samples or even the biomechanical results. Future research would be needed to prove the safety of these methods.

\subsection{Chemical acellularisation by solvents/detergents}

A newer promising approach is the extraction of cells by chemical solvents/detergents. The most widely used chemicals are sodium dodecyl sulphate (SDS, an ionic detergent), Triton$X$ (a non-ionic detergent) and tri-nitro-butyl phosphate (TnBP). They have been described to acellularize tissue and successful application was performed on small intestine (Badylak et al., 1995), the urinary bladder (Chen et al., 1999), the liver (Brown et al., 2006), arterial vasculature (Walles et al., 2003), dermis (Armour et al., 2006), heart valves (Cebotari et al., 2006) and oesophagus transplants (Bhrany et al. 2006; Gilbert et al., 2006) among others. In orthopaedic surgery there have been experiments using Graft jacket ${ }^{\circledR}$ in irreparable rotator cuff defects for tendon augmentation (Barber et al., 2006; Coons et al., 2006). Acellularization of tendons (Tischer et al., 2007; Gilbert et al., 2006) and meniscal samples (Sandmann et al. 2008; Stapleton et al., 2008) has caused further interest in this technique.

Bolland et al. aimed to produce a natural, acellular matrix from porcine bladder tissue for use as a scaffold in developing a tissue-engineered bladder replacement. They used fullthickness, intact porcine bladders, which were acellularised by distention and immersion in hypotonic buffer containing $0.1 \%(\mathrm{w} / \mathrm{v})$ SDS and nuclease enzymes. Histological analysis of the resultant matrices showed that they were completely acellular whereas the major structural proteins had been retained. Intracellularly, some poorly soluble proteins remained. The amount of DNA per mg dry weight of fresh porcine bladder was $2.8(+/-0.1)$ $\mu \mathrm{g} / \mathrm{mg}$ compared to $0.1(+/-0.1) \mu \mathrm{g} / \mathrm{mg}$ in acellularised bladder. In biomechanical testing the tensile testing indicated that acellularisation did not significantly compromise the tensile strength of the tissue. Cytotoxicity assays using porcine smooth muscle cell cultures excluded the presence of soluble toxins in the biomaterial (Bolland et al., 2007). A newer work by Gilbert et al. has shown that the presence of remaining intracellular DNA might not have as adverse effects as at first suspected. They examined the DNA content of commercially available ECM scaffold materials and compared their DNA content with scaffolds prepared in the laboratory using different acellularisation protocols. Most of the examined scaffolds still contained some amounts of DNA (4 out of 6 from the commercially available scaffolds and 2 out of 3 from the produced ECM scaffolds). Interestingly, scaffolds 
which retained higher amounts of DNA did not show worse results than the scaffolds with less DNA (Gilbert et al., 2008). In a work by Brown et al., it could be shown in an animal model that the presence of cellular components within the extracellular matrix scaffold modulates the phenotype of the macrophages participating in the host response following implantation. Scaffolds containing cellular components (even autologous cellular components), elicited a predominantly M1 type macrophage response, resulting in a more dense connective tissue and/or scarring. Acellular scaffolds, however, were observed to elicit a predominantly M2 type macrophage response, which results in a more constructive type of remodelling response (Brown et al., 2009).

In the same animal model (abdominal wall defect in rats covered with several ECM scaffolds, i.e. porcine small intestinal submucosa (SIS), noncrosslinked SIS, and autologous body wall ) the effect of macrophages that derive from peripheral blood in the degradation of ECM scaffolds was examined and Valentine et al. could show, that peripheral blood monocytes are required for the early and rapid degradation of both SIS scaffolds and autologous body wall, and that carbodiimide crosslinked SIS's are resistant to macrophagemediated degradation (Valentin et al., 2009). Apart from the macrophages the $T$ lymphocytes play a crucial role in organ rejection, especially in cell-mediated immune responses to xenografts (Strom et al., 1996). Th1 lymphocytes produce cytokines such as interleukin (IL)-2, interferon (IFN)- $\gamma$, and tumor necrosis factor (TNF)- $\alpha$, leading to macrophage activation, stimulation of complement and differentiation of CD8 ${ }^{+}$cells to a cytotoxic phenotype, which leads to transplant rejection (Chen et al., 1996). In contrast, Th2 lymphocytes produce IL-4, IL-5, IL-6, and IL-10, cytokines that do not activate macrophages. Resulting from this, the activation of the Th2 pathway is associated with transplant acceptance (Chen et al., 1995). The only ECM scaffold material for which the Th1/Th2 response has been characterized so far is small intestine ECM (Allman et al., 2001). Allman implanted SIS-ECM subcutaneously in mice and could show that the expression of IL-4 (Th2) was increased, while the expression of IFN- $\gamma$ (Th1) was markedly decreased by 100fold compared to the response elicited by the xenogeneic muscle group. Although there was an immune response to the SIS-ECM after implantation, this response was dominated by the Th2 pathway mediators, lacking an acute rejection.

Since similar studies have not been conducted for other forms of ECM scaffold materials, it is not possible to determine whether they would elicit the same type of host response. Thinking of the diversity of different tissues and scaffolds, it seems likely that the host response to biologic scaffolds will vary to a large degree following implantation. Further research is needed to understand the immunogenic reactions to the implanted scaffolds and the effects of acellularisation on the repopulation of these scaffolds. One step in this direction are two recent publications by Beattie et al. and Reing et al. who could show that the acellularisation process and the produced degradation products are important modulators for the recruitment and proliferation of appropriate cell types during the remodelling process (Beattie et al., 2009; Reing et al., 2009).

The first study using acellularized tissue in orthopaedic research was performed by Cartmell et al. (Cartmell et al., 2000). Therein, they investigated the effectiveness of treatment of rat tail tendons with SDS, Tri (n-butyl) phosphate and Triton- $X$ and found that both the treatment with SDS ( $1 \%$ for $24 \mathrm{~h})$ or TnBP $(1 \%$ for $48 \mathrm{~h})$ resulted in an acellular matrix with retention of almost normal histological structure. The biomechanical properties were similar to native tendons. In contrast, Triton-X ( $1 \%$ for $24 \mathrm{~h})$ disrupted the collagen fibers and 
was not as effective in acellularization as the two other methods, causing a disruption of the normal D-period of reconstituted rat tail tendon collagen fibers and an approximate $50 \%$ decrease in wet tensile strength and stiffness values. Following this, in 2004 Cartmell and Dunn could show that bone-patella-tendon-bone ligaments from rabbits could be successfully acellularized and reseeded with fibroblasts. Fibroblast proliferation rate was thereby slightly retarded on SDS- treated patellar tendons, whereas the repopulation in the TnBP- treated group was successful. Ingram et al. examined the additional effects of ultrasound on the repopulation process of natural tendon scaffolds acellularized with $0.1 \%$ SDS and found that repopulation with tenocytes was improved (Ingram et al., 2007). The work of Woods et al. compared the effectiveness of three extraction protocols in the development of an acellularized porcine bone-anterior cruciate ligament- bone graft (Woods et al. 2005). Therefore, they combined Triton-X (1\% for 24 hours) either with SDS (1\% for 24 hours) or TnBP ( $1 \%$ for 24 hours). The combination of Triton-X with SDS was most effective at removing cell nuclei and intracellular protein (vimentin) from the ACL but affected both the collagen and glycosaminoglycan (GAG) components of the extracellular matrix while increasing the tensile stiffness of the ligament. In contrast, the combination of Triton- $X$ with Triton- $X$ was least effective of the three treatments in terms of cellular extraction, anyway its use did not alter the mechanical (stiffness and failure load) and biochemical (collagen and GAG content) properties of the ACL compared to the control group significantly. TritonTnBP matched the level of decellularization achieved by Triton-SDS in terms of visible cell nuclei. It had lower effects on the extraction of the intracellular vimentin. Though TritonTnBP did change the collagen content of the ACL (significant reduction of collagen content), the mechanical properties (tensile stiffness, failure load) were left unaffected. Overall, all three decellularization treatments maintained adequate mechanical and biochemical properties of B-ACL-B grafts. In a study by Vavken et al. 2009 the effectiveness of the acellularization of porcine ACL with Triton-X ( $0.25 \%$ for 24 hours), SDS ( $0.1 \%$ for 24 hours) and trypsin ( $0.1 \%$ for 24 hours) was examined. All acellularization protocols reduced DNA content, with triton- $X$ treatment having the greatest effect. Concurrently, acellularization did not affect tissue collagen or total protein content, but did decrease glycosaminoglycan content. In this work Triton-X had the lowest effect on glycosaminoglycan depletion, so that the author favoured the acellularization with Triton-X. These different results show that future research is needed to find the most effective and most gentle way of acellularization to prepare the scaffold for repopulation.

For the acellularization of meniscal samples there is even more research needed. We could show (Sandmann et al., 2009) that the treatment of human meniscal samples with SDS $2 \%$ for 2 weeks is highly effective in acellularization (see chapter 5). In another work published by Stapleton et al. 2008 a different protocol was used for the acellularization of porcine meniscal samples. The menisci were acellularized by exposing the tissue to repetitive freezethaw cycles, incubation in hypotonic tris buffer, $0.1 \%(\mathrm{w} / \mathrm{v})$ sodium dodecyl sulfate in hypotonic buffer plus protease inhibitors, nucleases and hypertonic buffer followed by desinfection using $0.1 \%(\mathrm{v} / \mathrm{v})$ peracetic acid and final washing in phosphate-buffered saline. Histological, immunohistochemical, and biochemical analyses of the acellularized tissue confirmed the retention of the major structural proteins. However, a $59.4 \%$ loss of glycosaminoglycan content was noticed but with no significant alteration of the biomechanical characteristics. Furthermore, acellularized tissue and extracts were not cytotoxic to cells. 
Up to now, there are many unanswered questions regarding acelluarized scaffolds. The method of acellularization seems to be very promising of creating a collagen scaffold for tissue engineering of ligaments and meniscus, as the extracellular matrix and thereby the biomechanical properties are mainly preserved. However, in vivo animal studies are still missing. In the future acellularized tendons or meniscus samples might play a crucial role in orthopaedic surgery as do several extracellular matrix materials, which have been commercialized so far and are applied in a variety of indications reaching from the reconstruction of soft tissue defects (Ueno et al., 2004) to grafts in vascular surgery (Hiles et al., 1993) or neurosurgery (LeVisage et al., 2005).

\section{Repopulation of acellularized scaffolds}

The repopulation of acellularized tissue using detergents/solvents might improve and fasten incorporation and remodelling processes and thereby improve the long- term results. Cell proliferation on acellularized tissue is dependent on the used chemical treatment, with SDS showing the best acellularization rate but slightly diminished cell proliferation compared to Triton-X or TnbP (Gratzer et al., 2006, also see previous section).

In a study published by Cartmell in 2004 the seeding of acellularized tendons was most effective in TnBP treated tendons. They were seeded with fibroblasts and viable tissueengineered grafts could be created. These modified allografts could be developed into mechanically functional delivery vehicles for cells, gene therapy vectors, or other biological agents. Whereas multiple in vitro studies have been performed to repopulate acellular tissue (Cartmell et al., 2004; Gratzer et al., 2006), in vivo animal studies are sparse. In a study by Vavken et al. 2009 it could be shown that acellularized tendons treated with Triton-X could best be repopulated as the extracellular matrix was mainly unaffected. SDS treated tissue seems more difficult to repopulate, whereas it shows the best acellularization properties. Harrison et al., 2005 compared the effect of different culture condition variables (i.e. (1) the number of cells used for seeding, (2) the addition of epidermal growth factor (EGF), and (3) culture duration) on the repopulation of porcine ACL with fibroblasts. They found that Triton-X and TnBP acellularized ACL's were suitable for repopulation. Cellular ingrowth in the SDS group was successful, but less effective. At first it was supposed that this might be due to cytotoxic effects of SDS, but Gratzer et al., 2006 showed that not the cytotoxicity but probably matrix alterations were responsible for that.

Nevertheless, little is known about the optimal cell source for tissue engineering of ligaments. Van Eijk et al. 2004 searched for the optimal cell source for tissue engineering of the anterior cruciate ligament. They compared the use of bone marrow stromal cells (BMSCs), ACL fibroblasts and skin fibroblasts and seeded them onto a resorbable suture material [poly(L-lactide/glycolide) multifilaments] at five different seeding densities, and cultured them for up to 12 days. All cell types tested attached to the suture material, proliferated, and synthesized extracellular matrix rich in collagen type I. On day 12 the scaffolds seeded with BMSCs showed the highest DNA content $(p<0.01)$ and the highest collagen production ( $p<0.05$ for the two highest seeding densities). Scaffolds seeded with ACL fibroblasts showed the lowest DNA content and collagen production. Another interesting study examined the proliferation and survival of different cell types (ACL fibroblasts vs. skin fibroblasts) on ligament analogues in the harsh environment of the rabbit knee joint (Belincampini 1998). Liu et al 2008 concluded in their study, that BMSC are a 
better cell source than ACL fibroblasts when using silk scaffolds for ACL tissue engineering. The same conclusion was reached in the study be Ge et al. in 2005.

\section{Tissue engineering of the ACL - own work}

The aim of our study (Tischer et al. 2007) was to investigate investigate whether the treatment of rabbit semitendinosus tendons with SDS leads to cell free constructs and whether these could serve as a scaffold for tissue engineering of the ACL. Therefore allograft semitendinosus tendons were treated with SDS using a special protocol (see table 1).

\begin{tabular}{|l|l|l|}
\hline Day 1 & Deionized water & $24 \mathrm{~h}$ \\
\hline Day 2 & $1 \%$ SDS & $24 \mathrm{~h}$ \\
\hline Day 3 & Deionized water & $24 \mathrm{~h}$ \\
\hline Day 4 & $70 \%$ ethanol & $24 \mathrm{~h}$ \\
\hline Day 5 & Phosphate buffered saline (PBS) & Several times \\
\hline
\end{tabular}

Table 1. Acellularization protocol for rabbit semitendinosus tendons

Following the acellularization process, the tendons were seeded with autologous dermal fibroblasts. Therefore dermal fibroblasts were taken from a small skin biopsy, extracted and cultured for approximately 10 days until the cells were confluent. The cells were split and after confluence solutions were made with a cell number of $1.0 \times 10^{6}$ cells/ $0.5 \mathrm{ml}$ medium. This suspension was injected into the acellular tendons in line with the collagen fibres. Additionally, cell suspension was applied for 4 days to the tendon surface for outer settlement of the cells.

Following, the tendons were tested biomechanically and histologically. For biomechanical testing three groups were examined, being nine native tendons, nine acellular tendons and nine tendons seeded with autologous dermal fibroblasts for 4 days of culture. The load to failure test was performed on a universal material test machine (Modell Zwicki 1120, Fa. Zwick, Germany) with a preload of $2 \mathrm{~N}$. The load- to failure test was performed by increasing the tensile loading continuously with a speed of $10 \mathrm{~mm} / \mathrm{min}$. Apart from the load to failure the biomechanical properties elongation of tendon until rupture and the stiffness were recorded.

For histological examination six tendons were used in each group. As standard all longitudinal sections were stained with hematoxylin-eosin. For analysis of changes in the extracellular matrix, tendons from each group were stained with a panel of monoclonal antibodies directed against collagen 1, 3, 4, 6, Pro-collagen 1, versican and vimentin.

Histological staining with a standard Hematoxylin/Eosin staining revealed that all cells could be removed from the tendons and the constructs were cell-free (see figure 1). No more cell nuclei could be seen. The acellularization process lead to more interfascicular spaces in the SDS group. The group with the seeded tendon constructs lead to increased irregularities in the tendons. The cells were viable, but most of them did not show the typical spindle shape appearance. Survival of the cells was proven by immunohistochemical staining for pro-collagen I, the precursor molecule of collagen I, which was absent after acellularization but was found around the seeded cells after seeding. 


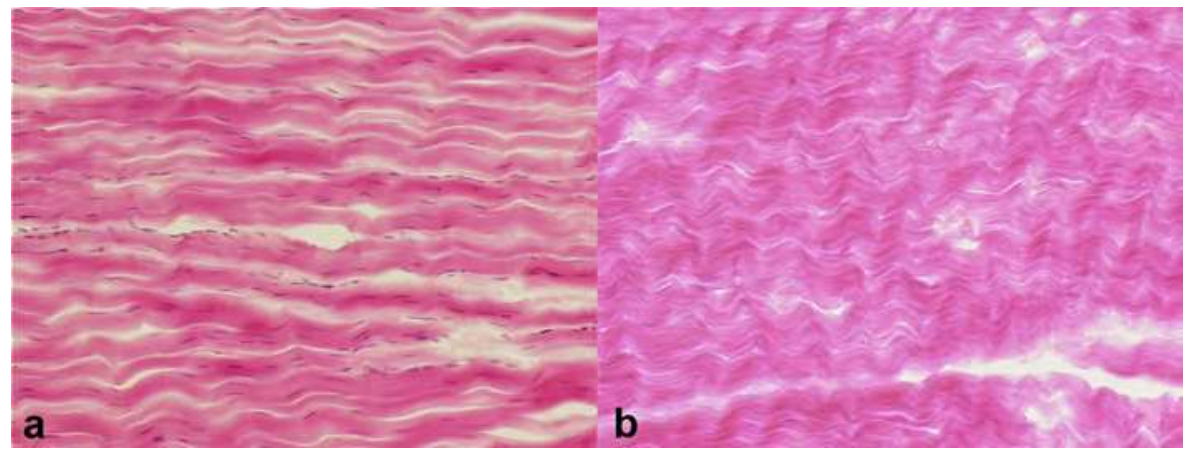

Fig. 1. Histological appearance of native (a) and acellular (b) rabbit semitendinosus tendon. No more cell nuclei can be found after acellularization (b). (HE staining, 100x magnification).

The treatment of the tendon constructs did not show any staining irregularities in the composition of the extracellular matrix. Staining for the collagens I, III, IV and VI did not show significant differences between the groups. Furthermore the distribution of macromolecules like versican was equally distributed in all three tested groups. Vimentin, an intermediary filament especially characteristic for fibroblasts was decreased, but clearly detectable.

\section{Biomechanical results}

For biomechanical testing nine native tendons, nine acellular tendons and nine cells seeded for 4 days were tested. The tests were done using a universal material test machine and with load- to failure testing. The maximum load to failure, the elongation of the tendon until rupture and the stiffness could be recorded (see table 2). The load to failure between the three groups was statistically not significant as is shown in the following table.

\begin{tabular}{|c|c|c|c|}
\hline & Load to failure & Stiffness & Elongation \\
\hline Native tendons & $134.5 \pm 12.9 \mathrm{~N}$ & $58.9 \pm 6.57 \mathrm{~N} / \mathrm{mm}$ & $2.47 \pm 0.33 \%$ \\
\hline Acellular tendons & $118.5 \pm 7.3 \mathrm{~N}$ & $48.5 \pm 3.05 \mathrm{~N} / \mathrm{mm}$ & $2.46 \pm 0.06 \%$ \\
\hline Seeded tendons & $132.3 \pm 5.6 \mathrm{~N}$ & $18.5 \pm 1.73 \mathrm{~N} / \mathrm{mm}$ & $7.50 \pm 0.5 \%$ \\
\hline
\end{tabular}

Table 2. Results of load to failure testing of rabbit semitendinosus tendons

The elongation of the seeded tendons as well as the stiffness were significantly elevated compared to the acellular or the native control group. The most evident explanation might be that the seeded tendons underwent a swelling process during cell culture, which was not compensated for by our only short pretensioning before testing. However, for comparability between the other groups, pretensioning was not changed.

\section{Animal model}

While the in vitro results of repopulated acellular scaffold were very promising, in vivo results are missing. Therefore the above described scaffold was tested in an in vivo rabbit model of ACL replacement (see figure 2). Therein we could show that SDS acellularized, allogenic constructs colonized with autologous fibroblasts (Tischer et al. 2009) had 
significantly weaker biomechanical properties than autologous tendons. In histological examination inflammatory reactions and acellular regions could be noticed, which might be due to the used acellularization method. However, since this is the first study in the field, more research as to be performed.

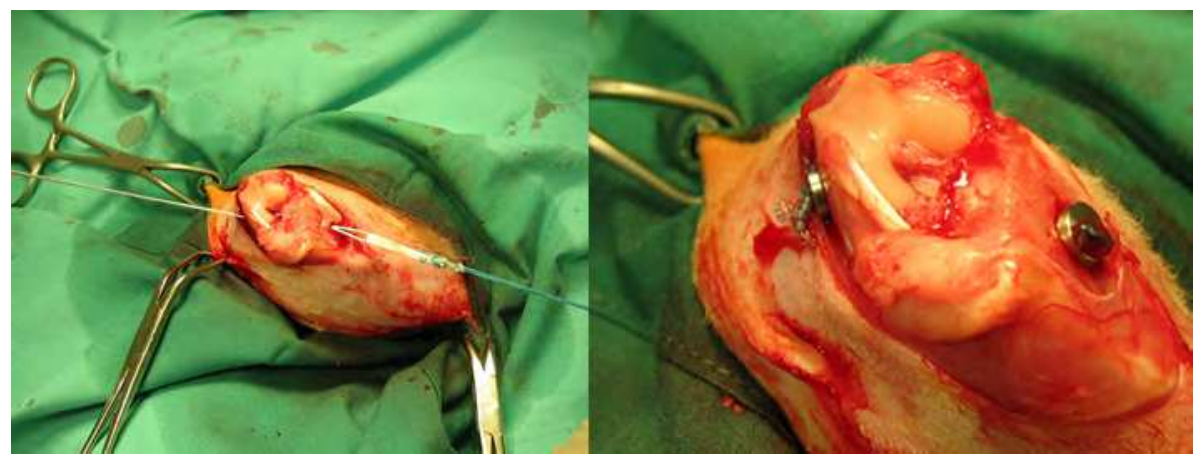

Fig. 2. Rabbit ACL replacement model using double stranded semitendinosus tendon at anatomical insertion site. Fixation was performed using custom made endobuttons.

A lot of ACL research has been done in the rabbit model and though it is a good animal model, future research in the field of double bundle research should take place in bigger animals, as their anatomy and the forces come closer to the forces in human knee joints. Questions, like the best fixation technique or the advantages of the double bundle reconstruction should be best addressed in bigger animals (Tischer et al., 2009).

\section{Discussion}

Solvents, like SDS or Triton- $X$ have been shown to be effective agents in acellularizing tissues. In our work we focussed on SDS and our results show that with the solvent SDS it is possible to acellularize tendon tissue. The advantage compared to other methods is that by the acellularization with SDS the constructs are made cell- free and all the cell- detritus is washed out as well. This makes them less immunogenic as the cell-based reactions do not take place in the same way. The acellularization with SDS has been shown to be most effective.

Secondly, SDS acellularized constructs can be reseeded again. This might be a little more difficult than when using other methods due to an alteration of extracellular matrix hindering repopulation (Gratzer et al., 2006), but it has been shown to work (Ingram et al., 2007). Acellular and repopulated scaffolds might be very useful in the future as the integration of transplants can thereby be improved. A small dermal biopsy followed by cell culture might be enough to create a "custom-fit" transplant. Future research has to be done in this field to evaluate the possibilities.

\section{Tissue engineering of the Meniscus - own work}

Tissue engineering of the meniscus is even more complex than that of ligaments or tendons, as the meniscus has an even more complex collagen network and most of the methods described before have lead to a failure in acellularization or a deterioration of the 
biomechanical properties. Inspired by the work mentioned above, we tried to apply the same acellularization protocol and initially failed. After gradually improving the SDS concentration and time we finally succeeded in acellularization using SDS for meniscus samples (see table 3). Since the diffusion of chemicals is time dependent, larger tissue specimens are expected to take longer before acellularization is achieved. A higher concentration of SDS ( $2 \%$ compared to $1 \%)$ and a longer duration were needed to get a cellfree meniscus construct.

\begin{tabular}{|l|l|l|}
\hline Day 1 & Deionized water & $24 \mathrm{~h}$ \\
\hline Day 2-14 & 2\% SDS & \\
\hline Day 15 & Deionized water & $24 \mathrm{~h}$ \\
\hline Day 16 & 70\% ethanol & $24 \mathrm{~h}$ \\
\hline Day 17 & Phosphate buffered saline (PBS) & Several times \\
\hline
\end{tabular}

Table 3. Extraction protocol for human meniscus constructs

\section{Histological and immunhistochemical results}

After treatment with SDS $2 \%$ for 2 weeks all meniscus samples (both medial and lateral) were identified as acellular by hematoxylin/eosin staining. Phase-contrast examinations revealed regular collagen bundle arrangement in the acellular specimens as seen in intact menisci. Immunohistochemically, no differences in the labelling patterns for collagen 1, 2 and 6 were observed when compared with intact menisci. Whereas for collagen I there was strong labelling in the whole meniscus, collagen 2 was labelled only in the fibrocartilaginous section of both groups. Collagen VI staining was evenly distributed throughout the meniscus tissue, both in acellularized and intact menisci.

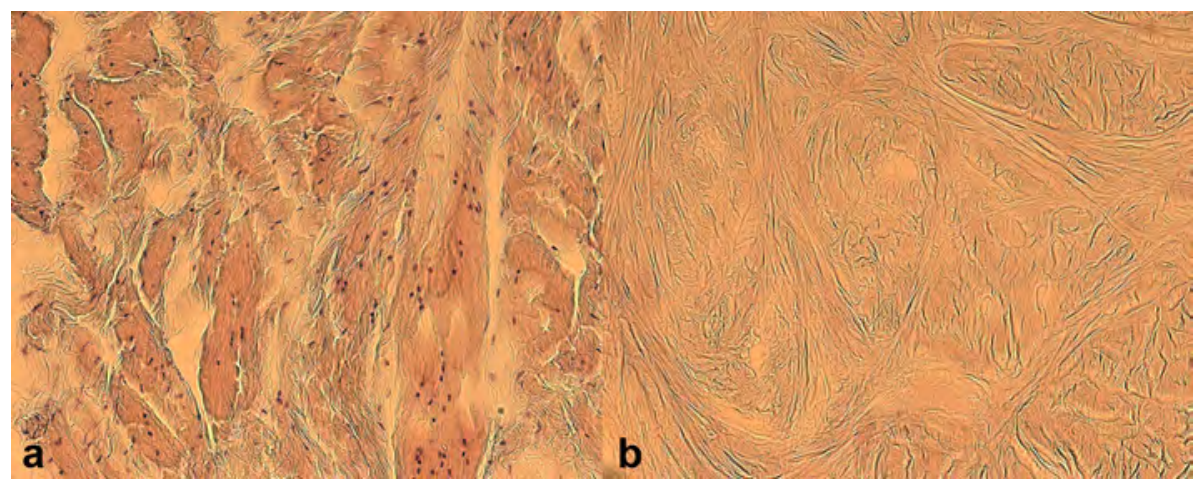

Fig. 3. Native (a) and acellular (b) meniscus samples at 200x magnification.

\section{Biomechanical results}

After the acellularization process a total of 5 medial and 5 lateral human menisci were examined using a ball indention test. The undersurface of the menisci was oriented perpendicular to the testing device. Three cylinders with a diameter of $5.0 \mathrm{~mm}$ and a height of $4.0 \mathrm{~mm}$ were punched out of each meniscus. These cylinders were put into a custommade device and the upper part of the cylinder was shaped to create a surface parallel to the base. The sample was then put into a custom-designed metallic plate with a circular cavity 
(diameter $5.0 \mathrm{~mm}$ and depth $4.0 \mathrm{~mm}$ ) to prevent the samples from dislocating during testing (see figure 4). The test was performed as a minimally constraint compression-relaxation test. During testing, the meniscus samples were kept moist using physiologic saline solution. A preload of $0.1 \mathrm{~N}$ was used and samples were checked intermittently during testing for displacement. The test cycle consisted of four phases: preloading of the sample with $0.1 \mathrm{~N}$; dynamic compression with a constant load velocity of $5 \mathrm{~mm} / \mathrm{min}$ until $7 \mathrm{~N}$; static compression of the sample for $60 \mathrm{~s}$ with a load of $7 \mathrm{~N}$; relaxation of the sample with a constant unload velocity of $1 \mathrm{~mm} / \mathrm{min}$ until a load of $0.15 \mathrm{~N}$. After an interval of $60 \mathrm{~s}$, the new test cycle started until a total number of five test cycles were reached. Load, indentor position, and time were displayed by the test software TestXpert and the following three biomechanical values could be calculated: (1) Relative sample compression calculated by the indentor position in relation to absolute sample height at the end of the dynamic compression phase (Compression is an indicator for viscosity and characterizes the ability of the tested tissue to evade the indenter) (2) ) Stiffness determined from the linear elastic slope of the loading curve between 2 and 5 N. High stiffness values mean high elasticity and vice versa. (3) Residual force (load measured at the end of the static compression phase). The residual force is influenced by the ability of tissue to evade the indenter in unconstraint compression (viscosity) as well as by the reset forces present in the tested tissue (elasticity). High residual forces show more elastic than viscous properties.

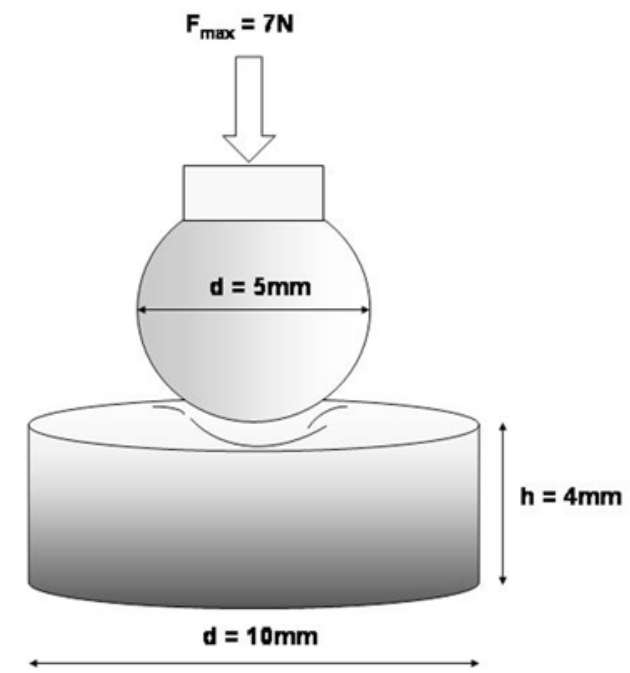

Fig. 4. Scheme of the ball indention trial (Sandmann et al., 2009).

The testing showed that the acellularization did not affect the biomechanical properties of the tested tissue. The test was performed with cyclic loading in 5 cycles with a maximum load of $7 \mathrm{~N}$. Between the cycles 60 seconds of relaxation were used. Stiffness increased significantly throughout testing by 162\% (native meniscus) and 143\% (acellular meniscus). During each testing cycle the differences between the two groups-intact meniscus and 
acellular scaffold-were not statistically significant. Mean compression of sample height was $32 \%( \pm 7.2 \%)$ for intact meniscus samples after the fifth cycle compared to $35 \%( \pm 8.3 \%)$ in the scaffolds. Scaffold compression exceeded compression of intact meniscus by $9 \%$, being not statistically significant $(\mathrm{p}>0.05)$. The residual force of the two groups increased after each cycle, but no statistically significant difference could be noticed. Biomechanical results were not significantly different comparing processed medial or processed lateral meniscus samples with the control group.

\begin{tabular}{|l|l|l|l|l|l|}
\hline & $\begin{array}{l}\text { Stiffness } \\
\text { (cycle 1) }\end{array}$ & $\begin{array}{l}\text { Stiffness } \\
\text { (cycle 5) }\end{array}$ & $\begin{array}{l}\text { Mean } \\
\text { compression } \\
\text { height after 5 } \\
\text { cycles }\end{array}$ & $\begin{array}{l}\text { Residual force } \\
\text { (cycle 1) }\end{array}$ & $\begin{array}{l}\text { Resiudal } \\
\text { force } \\
\text { (cycle 5) }\end{array}$ \\
\hline $\begin{array}{l}\text { Native } \\
\text { meniscus }\end{array}$ & $\begin{array}{l}11.6 \pm 3.2 \\
\mathrm{~N} / \mathrm{mm}\end{array}$ & $\begin{array}{l}31.1 \pm 3.3 \\
\mathrm{~N} / \mathrm{mm}\end{array}$ & $32 \%( \pm 7.2 \%)$ & $1.0 \pm 0.41 \mathrm{~N}$ & $\begin{array}{l}3.0 \pm 0.36 \\
\mathrm{~N}\end{array}$ \\
\hline $\begin{array}{l}\text { Acellular } \\
\text { meniscus }\end{array}$ & $\begin{array}{l}12.3 \pm 2.9 \\
\mathrm{~N} / \mathrm{mm}\end{array}$ & $\begin{array}{l}30 \pm 3.2 \\
\mathrm{~N} / \mathrm{mm}\end{array}$ & $35 \%( \pm 8.3 \%)$ & $3.1 \pm 0.4 \mathrm{~N}$ & $\begin{array}{l}3.2 \pm 0.41 \\
\mathrm{~N}\end{array}$ \\
\hline
\end{tabular}

Table 4. Results of biomechanical testing

\section{Discussion}

Comparable to the tissue engineering of tendons the treatment of human meniscus samples with the potent solvent SDS generated cell-free meniscus scaffolds. Theses scaffolds have been shown to be biomechanically stable with characteristics similar to native meniscus samples. Special caution was given to the different biomechanical characteristics of meniscus tissue compared to tendon tissue. Seeding of the acellularized menisci has not been tested so far but future research might have to answer the question, whether repopulation of meniscus samples is possible and whether the repopulation rates can be improved by different stimulation methods like mechanical stimuli generated in bioreactors.

\section{Outlook}

The ACL and the meniscus are the both structures in the knee joint which are frequently injured and so far in most cases no restoration of the original anatomy is possible. Especially the development of osteoarthrosis in the long term is still an unsolved problem. Fortunately, many advances have been made in the surgical reconstruction of the ACL and the disastrous total meniscectomy has been abandoned long ago. The role of new surgical techniques like double bundle ACL surgery still has to be found.

Apart from the acellularization of tissues, the use of growth factors, additionally or alone, seems to be a very promising option in improving the long- term results. Especially in meniscus transplants those factors that stimulate matrix synthesis and inhibit degradation of the extracellular matrix could be very useful. Future research has to point on the repopulation process and its improvement. Angiogenic growth factors might contribute to even further improve the results. Maybe the use of bioreactors producing adequate mechanical stimuli, growth factors or synthetic scaffolds (e.g. silk) will help to solve the remaining questions. 


\section{Conclusion}

Tissue engineering provides a lot of possibilities for improving tendon or meniscus scaffolds. Especially, the acellularization process with following cell seeding might be a very effective way of improving incorporation and remodelling processes as well as avoiding the cell-based immune reactions, which may be partially responsible for the deterioration of the allografts over the years. We have shown that the treatment of tendons or meniscus samples with the solvent SDS produces cell- free constructs. Despite acellularization, the extracellular matrix remains widely intact and the biomechanical properties remain unaltered. Whether the acellularization and the seeding will be successful in the long term has still to be shown in further animal models. Only then will human application be possible and improve operative treatment for our patients.

Big efforts have been made during the last years in vitro and in vivo and we believe that the tissue engineering of tendons and menisci samples might play a crucial role in the future of orthopaedic surgery.

\section{References}

Allman AJ, McPherson TB, Badylak SF, Merrill LC, Kallakury B, Sheehan C, Raeder RH, Metzger DW (2001). Xenogeneic extracellular matrix grafts elicit a TH2-restricted immune response, Transplantation 71, pp. 1631-1640

Allaire R; Muriuki M; Gilbertson L; Harner CD (2008). Biomechanical consequences of a tear of the posterior root of the medial meniscus. Similar to total meniscectomy. J Bone Joint Surg Am; Vol. 90; no. 9; 1922-31.

Armour AD; Fish JS; Woodhouse KA; Semple JL (2006). A comparison of human and porcine acellularized dermis: interactions with human fibroblasts in vivo. Plast Reconstr Surg; Vol. 117; No. 3, 845

Arnoczky SP; Warren RF (1983). The microvasculature of the meniscus and its response to injuries. An experimental study in the dog. American Journal of Sports Medicine. Vol. 11, No. 3, 131- 41.

Arnoczky SP (1983). Anatomy of the anterior cruciate ligament. Clin Orthop Relat Res.Vol 172,19-25

Aune A; Holm I; Risberg M; Jensen H; Steen H (2001). Four- strand hamstring tendon autograft compared with patellar tendon- bone autograft for anterior cruciate ligament reconstruction. American Journal of Sports Medicine; Vol. 32; 1639- 43

Badylak SF (2007). Review. The extracellular matrix as a biologic scaffold material. Biomaterials. Vol. 28, No. 25, 3587-93

Badylak SF, Freytes DO, Gilbert TW (2009). Extracellular matrix as a biological scaffold material: Structure and function. Acta Biomater. Vol. 5, No. 1, 1-13.

Badylak SF; Tullius R; Kokini K; Shelbourne KD; Klootwyk T; Voytik SL; Kraine MR; Simmons C (1995). The use of xenogeneic small intestinal submucosa as a biomaterial for Achilles tendon repair in the dog model. J Biomed Mater Res; Vol. 29; No 8; 977

Barber FA; Herbert MA; Coons DA (2006): Tendon augmentation grafts: biomechanical failure loads and failure patterns. Arthroscopy; Vol. 22; No. 5; 534-8 
Beard D; Anderson J; Davies S; Price A; Dodd C (2001). Hamstring vs. patella tendon for anterior cruciate ligament reconstruction: a randomised controlled trial. Knee; Vol. $8 ; 45-50$.

Bellincampi LD, Closkey RF, Prasad R, Zawadsky JP, Dunn MG (1998).Viability of fibroblast-seeded ligament analogs after autogenous implantation. J Orthop Res; Vol. 16; No. 4; 414-20.

Beattie AJ, Gilbert TW, Guyot JP, Yates AJ, Badylak SF. (2009). Chemoattraction of progenitor cells by remodeling extracellular matrix scaffolds. Tissue Eng Part A; Vol. 15; No. 5:1119-25.

Bhrany AD; Beckstead BL; Lang TC; Farwell DG; Giachelli CM; Ratner BD (2006). Development of an oesophagus acellular matrix tissue scaffold. Tissue Eng; Vol. 12; 319-30

Bolland F, Korossis S, Wilshaw SP, Ingham E, Fisher J, Kearney JN, Southgate J (2007). Development and characterisation of a full-thickness acellular porcine bladder matrix for tissue engineering. Biomaterials. Vol. 28; No 6:1061-70

Brown B; Lindberg K; Reing J; Stolz DB; Badylak SF (2006). The basement membrane component of biologic scaffolds derived from extracellular matrix. Tissue Eng; Vol. 12; No. 3; 519

Brown BN, Valentin JE, Stewart-Akers AM, McCabe GP, Badylak SF (2009). Macrophage phenotype and remodeling outcomes in response to biologic scaffolds with and without a cellular component. Biomaterials; Vol. 8:1482-91

Brucker PU; Lorenz S; Imhoff AB (2006). Aperture fixation in arthroscopic anterior cruciate ligament double-bundle reconstruction. Arthroscopy; Vol. 22; No 11; 1250.e1-6

Bryant AL; Pua YH; Clark RA (2009). Morphology of knee extension torque-time curves following anterior cruciate ligament injury and reconstruction. J Bone Joint Surg Am; Vol. 91; No. 6; 1424- 31

Buck RE; Malinin T; Brown MD (1989). Bone transplantation and human immunodeficiency virus: an estimate of risk of AIDS. Clin Orthop, Vol. 240; No. 129

Buma P; van Tienen T; Veth R (2007). The collagen meniscus implant. Expert Rev Med Devices; Vol. 4; No. 4; 507-16. Review

Busam ML, Rue JP, Bach BR Jr.(2007). Fresh-frozen allograft anterior cruciate ligament reconstruction.Clin Sports Med. Vol. 26; No.4:607-23

Carey JL; Dunn WR; Dahm DL; Zeger SL; Spindler KP (2009). A systematic review of anterior cruciate ligament reconstruction with autograft compared with allograft. J Bone Joint Surg Am; Vol. 91; No. 9; 2242-50

Cartmell JS; Dunn MG. (2000). Effect of chemical treatments on tendon cellularity and mechanical properties. J Biomed Mater Res. 2000 Jan;49(1):134-40.

Cartmell JS, Dunn MG. Development of cell-seeded patellar tendon allografts for anterior cruciate ligament reconstruction. Tissue Eng. 2004 Jul-Aug;10(7-8):1065-75

Cebotari S; Lichtenberg A; Tudorache I; Hilfiker A; Mertsching H; Leyh R; Breymann T; Kallenbach K; Maniuc L; Batrinac A; Repin O; Maliga O; Ciubotaru A; Haverich A (2006). Clinical application of tissue engineered human heart valves using autologous progenitor cells. Circulation; Vol. 14; No.1; 1132

Chen N, Field EH. (1995). Enhanced type 2 and diminished type 1 cytokines in neonatal tolerance, Transplantation, Vol. 59: 933-941 
Chen N, Gao Q, Field EH. (1996). Prevention of Th1 response is critical for tolerance. Transplantation Vol.61:1076-1083.

Chen F; Yoo JJ; Atala A (1999). Acellular collagen matrix as possible "off the shelf" biomaterial for urethral repair. Urology; Vol. 54; No. 2; 407

Coons DA; Barber AF (2006): Tendons graft substitutes- rotator cuff patches. Sports Med Arthrosc; Vol. 14; No. 3; 185-90

Crawford MJ; Swenson CL; Arnoczky SP; O’Shea J; Ross H (2004). Lyophilzation does not inactivate infectious retrovirus in systemically infected bone and tendon allografts. American Journal of Sports Medicine, Vol. 32, No. 3.

Curran AR; Adams DJ; Gill JL; Steiner ME; Scheller AD (2009). The biomechanical effects of low- dose irradiation on bone- patellar- tendon- bone allograft. American Journal of Sports Medicine; Vol. 32; No. 5; 1131-1135.

Diehl P; Schauwecker J; Mittelmeier W; Schmitt M (2008). High hydrostatic pressure, a novel approach in orthopedic surgical oncology to disinfect bone, tendons and cartilage. Anticancer Res; Vol. 28; No. 6B; 3877- 83.

Diehl P; Steinhauser E; Gollwitzer H; Heister C; Schauwecker J; Milz S; Mittelmeier W; Schmitt M. (2006). Biomechanical and immunhistochemical analysis of high hydrostatic pressure-treated Achilles tendons. J Orthop Sci . Vol. 11: 380-385

Fideler BM; Vangsness CT; Lu B (1995). Gamma irradiation: effects on biomechanical properties of human bone- patellar- bone allografts. American Journal of Sports Medicine, Vol. 23: 643- 646.

Ge Z; Goh JC; Lee EH (2005). Selection of cell source for ligament tissue engineering. Cell Transplant. Vol. 14; No 8; 573-83.

Gelber PE; Gonzalez G; Lloreta JL; Reina F; Caceres E; Monllau JC (2008). Freezing causes changes in the meniscus collagen net: a new ultrastructural meniscus disarray scale. Knee Surg Sports Traumatol Arthrosc; Vol. 16; No. 4:353-9

Gelber PE; Gonzalez G; Torres R; Garcia Giralt N; Caceres E; Monllau JC (2009). Cryopreservation does not alter the ultrastructure of the meniscus. Knee Surg Sports Traumatol Arthrosc; Vol.17; No 6:639-44

Gibbons MJ, Butler DL, Grood ES, Bylski-Austrow DI, Levy MS, Noyes FR (1991). Effects of gamma irradiation on the initial mechanical and material properties of goat bonepatellar tendon-bone allografts. J Orthop Res; Vol. 9; No. 2; 209-18

Gilbert TW, Freundb S JM, Badylak SF (2008). Quantification of DNA in Biologic Scaffold Materials. J Surg Res. Vol. 152; No. 1; 135-39

Gilbert TW; Sellaro TL; Badylak SF (2006). Decellularization of tissues and organs. Biomaterials; Vol. 27; 3675-83

Gratzer PF, Harrison RD, Woods T (2006).Matrix alteration and not residual sodium dodecyl sulfate cytotoxicity affects the cellular repopulation of a decellularized matrix. Tissue Eng.; Vol. 12; No. 10; 2975-83.

Harrison RD, Gratzer PF.(2005). Effect of extraction protocols and epidermal growth factor on the cellular repopulation of decellularized anterior cruciate ligament allografts. J Biomed Mater Res AVol. 75; No.4:841-54.

Hiles MC; Badylak SF; Geddes LA; Kokini K; Morff RJ (1993). Porosity of porcine small intestinal submucosa for use as a vascular graft. J Biomed Mater Res; Vol. 27; No. 2; $139-44$ 
Ingram JH, Korossis S, Howling G, Fisher J, Ingham E. (2007). The use of ultrasonication to aid recellularization of acellular natural tissue scaffolds for use in anterior cruciate ligament reconstruction. Tissue Eng. Vol. 13; No. 7:1561-72.

Kartus J; Movin T; Karlsson J (2001). Donor-site morbidity and anterior knee problems after anterior cruciate ligament reconstruction using autografts. Arthroscopy; Vol 17; No. 9; 971- 80.

Kondo E, Yasuda K, Azuma H, Tanabe Y, Yagi T (2008). Prospective clinical comparisons of anatomic double-bundle versus single-bundle anterior cruciate ligament reconstruction procedures in 328 consecutive patients. American Journal of Sports Medicine; Vol. 36; No. 9, 1675-87

Krych AJ; Jackson JD; Hoskin TL; Dahm DL (2007). A meta-analysis of patellar tendon autograft versus patellar tendon allograft in anterior cruciate ligament reconstruction. Arthroscopy; Vol. 24; No. 3; 292-8

LeVisage C; Okawa A; Kadakia L; Yang S., Sieber AN; Kostuik JP (2005). Intervertebral disc regeneration using small intestinal submucosa as a bioscaffold. Comput Meth Biomech Biomed Eng; Suppl 1; No. 177

Lewis PB, Williams JM, Hallab N, Virdi A, Yanke A, Cole BJ (2008). Multiple freeze-thaw cycled meniscal allograft tissue: A biomechanical, biochemical, and histologic analysis. J Orthop Res. Vol. 26; No 1:49-55.

Liu H; Fan H; Toh SL; Goh JC (2008). A comparison of rabbit mesenchymal stem cells and anterior cruciate ligament fibroblasts responses on combined silk scaffolds. Biomaterials. Vol. 29; No. 10; 1443-53

Lohmander LS, Englund PM, Dahl LL, Roos EM (2007). The long-term consequence of anterior cruciate ligament and meniscus injuries: osteoarthritis. American Journal of Sports Medicine ; Vol. 35, No. 10, 1756-69.

Mahirogullari M; Ferguson CM; Whitlock PW; Stabile KJ; Poehling GG (2007). Freeze- dried allografts for anterior cruciate ligament reconstruction. Clin Sports Med; Vol 26; No. 4 ; 625- 37

Maier D; Braeun K; Steinhauser E; Ueblacker P; Oberst M; Kreuz PC; Roos N; Martinek V; Imhoff $A B$ (2007). In vitro analysis of an allogenic scaffold for tissue-engineered meniscus replacement. J Orthop Res.; Vol. 25; No. 12; 1598-608

Makihara Y; Nishino A; Fukubayashi T; Kanamori A (2006). Decrease of knee flexion torque in patients with ACL reconstruction: combined analysis of the architecture and function of the knee flexor muscles. Knee Surg Sports Traumatol Arthrosc; Vol 14; 310-17

Martinek V, Ueblacker P, Bräun K, Nitschke S, Mannhardt R, Specht K, Gansbacher B, Imhoff $A B$ (2006). Second generation of meniscus transplantation: in-vivo study with tissue engineered meniscus replacement. Arch Orthop Trauma Surg; Vol. 126; No $4 ; 228-34$

Muren O, Dahlstedt L, Brosjö E, Dahlborn M, Dalén N. (2005). Gross osteolytic tibia tunnel widening with the use of Gore-Tex anterior cruciate ligament prosthesis: a radiological, arthrometric and clinical evaluation of 17 patients 13-15 years after surgery. Acta Orthop; Vol. 76; No. 2; 270-4

Nakamura N; Horibe S; Sasaki S; Kitaguchi T; Tagami M; Mitsuoka T; Toritsuka Y; Hamada M; Shino K (2002). Evaluation of active knee flexion and hamstring strength after anterior cruciate ligament reconstruction using hamstring tendons. Arthroscopy; Vol. 8; 337-42 
Packer JD; Rodeo SA (2009). Meniscal allograft transplantation. Clin Sports Med; Vol. 28; No. 2; 259-83

Park HJ; Urabe K; Naruse K; Onuma K; Nemoto N; Itoman M (2009). The effect of cryopreservation or heating on the mechanical properties and histomorphology of rat bone-patellar tendon-bone. Cell Tissue Bank; Vol; 10; No. 1; 11-18

Reing JE; Zhang L; Myers- Irvine J; Cordero KE; Freytes DO; Heber- Katz E; Bedelbaeva K; McIntosh D; Dewilde A; Braunhut SJ; Badylak SF 2009. Degradation products of extracellular matrix affect cell migration and proliferation. Tissue Engineering ; Vol 15; No. 3; 605-13

Roolker W, Patt TW, van Dijk CN, Vegter M, Marti RK (2000). The Gore-Tex prosthetic ligament as a salvage procedure in deficient knees. Knee Surg Sports Traumatol Arthrosc; Vol. 8; No. 1; 20-5.

Sandmann GH; Eichhorn S; Vogt S; Adamczyk C; Aryee S; Hoberg M; Milz S; Imhoff AB; Tischer T (2009). Generation and characterization of a human acellular meniscus scaffold for tissue engineering. Journal of Biomedical Materials Research, Part A; Vol. 91A; No. 2; 567- 74.

Sass K, Corterier C, Brylla E, Löffler S, Steen M, Spanel-Borowski K(2009). Cryopreserved porcine tendons preserve cell viability after thawing. Transplant Proc. Vol. 41; No. 5:1911-3.

Stapleton TW, Ingram J, Katta J, Knight R, Korossis S, Fisher J, Ingham E (2008). Development and characterization of an acellular porcine medial meniscus for use in tissue engineering.Tissue Eng Part A; Vol. 14; No. 4:505-18.

Strom TB, Roy-Chaudhury P, Manfro R, Zheng XX, Nickerson PW, Wood K; Bushell A (1996) The Th1/Th2 paradigm and the allograft response. Curr Opin Immunol; Vol 8: 688-693.

Sun K, Tian S, Zhang J, Xia C, Zhang C, Yu T (2009). Anterior cruciate ligament reconstruction with $\mathrm{BPTB}$ autograft, irradiated versus non-irradiated allograft: a prospective randomized clinical study. Knee Surg Sports Traumatol Arthrosc. Vol. 17; No. 5; 464-74.

Tashiro T; Kurosawa H; Kawakami A; Hikita A; Fukui N (2003). The influence of medial tendon harvest on knee flexor strength after anterior cruciate ligament reconstruction: a detailed evaluation with comparison of single- and double tendon harvest; American Journal of Sports Medicine; Vol 31; 522- 29.

Taylor DC; Posner M; Curl WW; Feagin JA (2009).Isolated tears of the anterior cruciate ligament: over 30-year follow-up of patients treated with arthrotomy and primary repair. American Journal of Sports Medicine; Vol. 37; No. 1, 65-71

Tischer T, Milz S, Maier M, Schieker M, Benjamin M (2002). An immunohistochemical study of the rabbit suprapatella, a sesamoid fibrocartilage in the quadriceps tendon containing aggrecan. J Histochem Cytochem; Vol.50; No.7:955-60

Tischer T; Ronga M; Tsai A; Ingham SJ; Ekdahl M; Smolinski P; Fu FH (2009). Biomechanics of the goat three bundle anterior cruciate ligament. Knee Surg Sports Traumatol Arthrosc; Vol. 17; N0. 8; 935-40.

Tischer T; Vogt S; Aryee S; Steinhauser E; Adamczyk C; Milz S; Martinek V; Imhoff AB (2007). Tissue engineering of the anterior cruciate ligament: a new method using acellularized tendon allografts and autologous fibroblasts. Arch Orthop Trauma Surg, Vol. 127, 735- 741. 
Tischer T; Aryee S; Wexel G; Steinhauser E; Adamczyk C; Eichhorn S; Milz S; Martinek V; Gänsbacher B; Imhoff AB; Vogt S. Tissue Engineering of the ACL - SDS Chemically Acellularized and Revitalized Tendons are Inferior to Native

Tendons. Tissue Engineering, accepted 2009

Ueno T; Pickett LC; de la Fuente SG; Lawson DC; Pappas TN (2004). Clinical application of porcine small intestinal submucosa in the management of infected or potentially contaminated abdominal defects. J Gastrointest Surg; Vol. 8; No. 1, 109- 112

Valentin JE, Stewart-Akers AM, Gilbert TW, Badylak SF (2009). Macrophage participation in the degradation and remodeling of extracellular matrix scaffolds. Tissue Eng Part A. Vol. 15; No. 7:1687-94

Van Eijk F, Saris DB, Riesle J, Willems WJ, Van Blitterswijk CA, Verbout AJ, Dhert WJ (2004). Tissue engineering of ligaments: a comparison of bone marrow stromal cells, anterior cruciate ligament, and skin fibroblasts as cell source. Tissue Eng.; Vol. 10; No. 5-6; 893-903.

Van Tienen TG; Hannink G; Buma P (2009). Meniscus replacement using synthetic materials. Clin Sports Med. Vol. 28; No. 1; 143-56.

Van Thiel GS; Verma N; Yanke A; Basu S; Farr J; Cole B (2009). Meniscal allograft size can be predicted by height, weight, and gender. Arthroscopy. Vol. 25; No. 7; 722-7.

Vavken P; Joshi S; Murray MM (2009). Triton-X is most effective among three decellularization agents for ACL tissue engineering. Journal of Orthopaedic Research.

Verdonk PC; Verstraete KL; Almqvist KF; DeCuyper K; Veys EM; Verbruggen G; Verdonk R (2006). Meniscal allograft transplantation: long-term clinical results with radiological and magnetic imaging correlations. Knee Surg Sports Traumatol Arthrosc; Vol. 14; 694-706

Walles T; Herden T; Haverich A; Mertsching H (2003). Influence of scaffold thickness and scaffold composition on bioartificial graft survival. Biomaterials; Vol. 24; No 7; 1233

Wirth CJ; Peters G; Milachowski KA; Weismeier KG; Kohn D (2002). Long-term results of meniscal allograft transplantation. American Journal of Sports Medicine; Vol. 30; No. 2 ; $174-81$

Woods T, Gratzer PF (2005). Effectiveness of three extraction techniques in the development of a decellularized bone-anterior cruciate ligament-bone graft; Biomaterials; Vol. 26; No. 35; 7339-49

Zaffagnini S, Marcheggiani Muccioli GM, Chatrath V, Bondi A, De Pasquale V, Martini D, Bacchelli B, Marcacci M. (2008). Histological and ultrastructural evaluation of Leeds-Keio ligament 20 years after implant: a case report. Knee Surg Sports Traumatol Arthrosc. Vol. 16; No. 11; 1026-9

Zantop T, Wellmann M, Fu FH, Petersen W (2008) Tunnel positioning of anteromedial and posterolateral bundles in anatomic anterior cruciate ligament reconstruction: anatomic and radiographic findings American Journal of Sports Medicine; Vol. 36; No $1 ; 65-72$. 


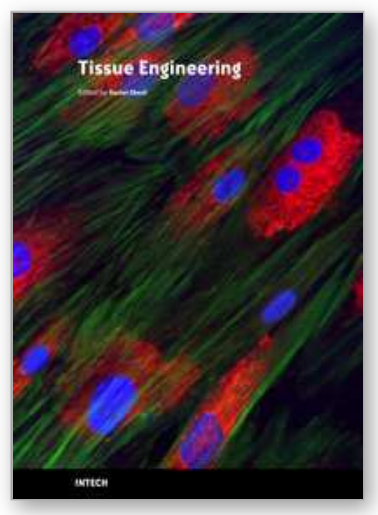

\author{
Tissue Engineering \\ Edited by Daniel Eberli
}

ISBN 978-953-307-079-7

Hard cover, 524 pages

Publisher InTech

Published online 01, March, 2010

Published in print edition March, 2010

The Tissue Engineering approach has major advantages over traditional organ transplantation and circumvents the problem of organ shortage. Tissues that closely match the patient's needs can be reconstructed from readily available biopsies and subsequently be implanted with minimal or no immunogenicity. This eventually conquers several limitations encountered in tissue transplantation approaches. This book serves as a good starting point for anyone interested in the application of Tissue Engineering. It offers a colorful mix of topics, which explain the obstacles and possible solutions for TE applications.

\title{
How to reference
}

In order to correctly reference this scholarly work, feel free to copy and paste the following:

Gunther H. Sandmann and Thomas Tischer (2010). Tissue Engineering of the Anterior Cruciate Ligament and Meniscus Using Acellularized Scaffolds, Tissue Engineering, Daniel Eberli (Ed.), ISBN: 978-953-307-079-7, InTech, Available from: http://www.intechopen.com/books/tissue-engineering/tissue-engineering-of-theanterior-cruciate-ligament-and-meniscus-using-acellularized-scaffolds

\section{INTECH}

open science | open minds

\section{InTech Europe}

University Campus STeP Ri

Slavka Krautzeka 83/A

51000 Rijeka, Croatia

Phone: +385 (51) 770447

Fax: +385 (51) 686166

www.intechopen.com

\section{InTech China}

Unit 405, Office Block, Hotel Equatorial Shanghai

No.65, Yan An Road (West), Shanghai, 200040, China

中国上海市延安西路65号上海国际贵都大饭店办公楼405单元

Phone: +86-21-62489820

Fax: $+86-21-62489821$ 
(C) 2010 The Author(s). Licensee IntechOpen. This chapter is distributed under the terms of the Creative Commons Attribution-NonCommercialShareAlike-3.0 License, which permits use, distribution and reproduction for non-commercial purposes, provided the original is properly cited and derivative works building on this content are distributed under the same license. 